\title{
Erratum to: Computing maximal and minimal trap spaces of Boolean networks
}

\author{
Hannes Klarner $^{1} \cdot$ Alexander Bockmayr $^{1} \cdot$ Heike Siebert $^{1}$
}

Published online: 10 January 2017

(C) Springer Science+Business Media Dordrecht 2017

\section{Erratum to: Nat Comput (2015) 14:535-544 DOI 10.1007/s11047-015-9520-7}

The subtitles in Fig. 2 were the wrong way around, and some of the transitions were false.

Figure 2 has been corrected and provided below.

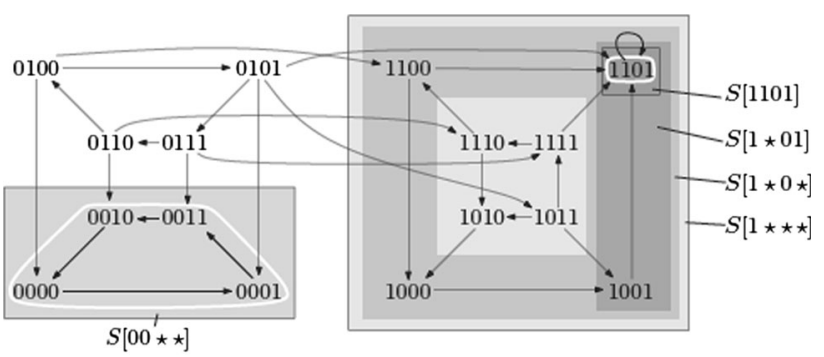

(a) The asynchronous transition graph $(S, \rightarrow)$

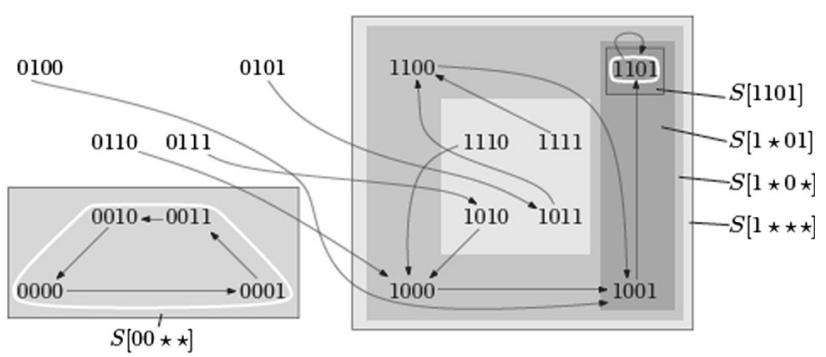

(b) The synchronous transition graph $(S, \hookrightarrow)$

Fig. 2 Synchronous and asynchronous transition graphs of the running example. The trap spaces (and the way they are nested) are given as a heat map. Minimal and maximal trap spaces are outlined by a black line and the attractors by a white line. Using the " $\star$ " notation, we get the following sets: $S_{\rightarrow}^{\star}=\{\star \star \star \star, 00 \star \star, 1 \star \star \star$, $1 \star 0 \star, 1 \star 01,1101\}, \min \left(S_{\rightarrow}^{\star}\right)=\{00 \star \star, 1101\}$ and $\max \left(S_{\rightarrow}^{\star}\right)=$ $\{00 \star \star, 1 \star \star \star\}$ and $S_{F}=\{1101\}$

The online version of the original article can be found under doi: 10.1007/s11047-015-9520-7.

\section{Hannes Klarner}

hannes.klarner@fu-berlin.de

1 Freie Universität Berlin, FB Mathematik und Informatik, Arnimallee 6, 14195 Berlin, Germany 